\title{
Well-Water Consumption and Risk of Parkinson's Disease: A Meta-Analysis of I5 Observational Studies
}

\author{
Yanni Shi ${ }^{1}$ \\ Kezhong Zhang ${ }^{2}$ \\ Ming $\mathrm{Ye}^{3}$ \\ 'School of Stomatology, Nanjing Medical \\ University, Nanjing, 210029, People's \\ Republic of China; ${ }^{2}$ Department of \\ Neurosurgery, The First Affiliated \\ Hospital of Nanjing Medical University, \\ Nanjing, 210029, People's Republic of \\ China; ${ }^{3}$ Department of Neurosurgery, \\ The First Affiliated Hospital of Suzhou \\ University, Suzhou, 215000, People's \\ Republic of China
}

\begin{abstract}
Introduction: The relationship between the risk of Parkinson disease and well-water consumption has been extensively studied, but the results have been contradictory. Therefore, we conducted a meta-analysis of observational studies to systematically assess the relationship between well-water consumption and Parkinson disease risk.

Methods: We followed the PRISMA checklist in completing the meta-analysis. We searched two electronic databases (PubMed, EBSCO, EMBASE and Cochrane) from establishment to October, 2021, to identify relevant studies linking well-water drinking to Parkinson risk. We used a random-effects model to calculate the overall odds ratio (OR) with $95 \%$ confidence interval (CI). To reduce intragroup heterogeneity, we conducted subgroup analyses according to the research design and geographic area.

Results: After careful review, a total of 15 case-control-designed studies included data suitable for our meta-analysis. The total number of cases and total controls that contribute to the combined OR were 2182 and 2456 . The combined OR for ever well-water drinkers versus non-drinkers was 1.16 (95\% CI: $\left.0.97-1.39, \mathrm{I}^{2}=44.52 \%\right)$. In subgroup analysis by geographic area, a significant association was observed in studies conducted in Asia (OR 1.29, 95\% CI: $1.05-1.58, \mathrm{I}^{2}=0.0 \%$, $\mathrm{p}$ for heterogeneity $=0.460)$ but not in studies conducted in America (OR 0.97, 95\% CI: 0.76-1.24, $\mathrm{I}^{2}=41.2 \%$, p for heterogeneity $\left.=0.164\right)$. In subgroup analysis by study design, a borderline significant association emerged in hospital-based case-control studies (OR 1.31, 95\% CI: 1.04 $1.65, \mathrm{I}^{2}=40.9 \%$, p for heterogeneity $\left.=0.118\right)$ but not in population-based case-control studies $(\mathrm{OR}$ $0.96,95 \% \mathrm{CI}: 0.73-1.26, \mathrm{I}^{2}=41.1 \%$, $\mathrm{p}$ for heterogeneity $=0.165$ ).
\end{abstract}

Discussion: Our results indicate that there is no significant correlation between well-water consumption and PD risk.

Keywords: Parkinson's disease, well-water consumption, meta-analysis, risk factor

\section{Introduction}

Parkinson disease (PD) is one of the most common neurodegenerative diseases. Globally, approximately $2 \%$ of people over age 60 year and $4 \%$ of people over age 80 years are affected by $\mathrm{PD} .^{1}$ Much research has been conducted to explore possible PD risk factors and protective factors. ${ }^{2-5}$ Among the possible risk factors, different designs have been used to extensively study the consumption of well water, and many studies report that the use of well water may increase the risk of $\mathrm{PD},{ }^{6-11}$ however, other studies have observed a reverse correlation or no correlation. ${ }^{12-15}$ Thus it remains unclear whether there is a causal relationship between well-water consumption and PD risk. ${ }^{16}$

Existing studies have proved pathologically that there is a positive correlation between PD and some substances in pesticides (such as Rotenone). Therefore, we
Correspondence: Kezhong Zhang; Ming Ye Email zhangkezhong9@I26.com; yeming@suda.edu.cn 
speculate that the pathological basis for well water to cause PD could be that it functions as a medium of pesticides and other harmful substances. However, the content of various substances in the well water may be affected by factors such as the differences in the geographical environment. This is cause disparities in conclusions.

To clarify this issue, we conducted a meta-analysis of published observational studies. After careful review, a total of 15 case-control-designed studies included data suitable for our meta-analysis, most of which are from Asia, Europe and North America. The included studies were all case-control studies. Participants comprised patients with PD and controls without PD. We investigated whether there was a difference in the exposure ratio of using well water as drinking water between the two groups to determine whether there is a connection between drinking well water and PD.

\section{Materials and Methods}

\section{Search Strategy}

We identified eligible studies in this systematic review and meta-analysis by conducting a search of the PubMed, EBSCO, EMBASE and Cochrane databases to October 2021. We used the search terms (well-water drinking OR well-water consumption OR well water OR rural life OR country life) AND (Parkinson's disease OR Parkinson's OR Parkinson disease OR Parkinson).

\section{Inclusion Criteria}

We adopted the following inclusion criteria: (1) casecontrol design; (2) average age of participants more than 40 years; (3) diagnosis of clinically probable or possible PD if patients met the following criteria: 1) manifestation of at least two of the following symptoms: resting tremor, bradykinesia, or cogwheel rigidity; 2) no suggestion of parkinsonian syndrome owing to trauma, brain tumor, infection, cerebrovascular disease, other known neurologic disease, or treatment with dopamine-blocking or dopamine-depleting agents; 3) no atypical features such as prominent oculomotor palsy, cerebellar signs, vocal cord paresis, severe orthostatic hypotension, pyramidal signs, amyotrophy, or limb apraxia; 4) asymmetric onset; and 5) if treatment with levodopa had been initiated, symptomatic improvement after treatment. (4) sufficient data to calculate odd ratio[OR] with corresponding 95\% confidence interval [CIs]; and (5) the language used is English.

We excluded studies for the following reasons: (1) unable to extract valid outcome data from the report; (2) more than one report based on the same study population published, in which case only the most comprehensive publication was included in this meta-analysis; (3) unable to obtain the full text; (4) the sample size was too large or too small (sample size less than 60 or more than 10,000); studies with a very large sample size were analyzed separately.

\section{Data Extraction and Assessment of Methodological Quality}

Data extraction and research quality assessment were conducted by the same reviewer. The following data were extracted: first author's last name, year of publication, country, study design, sample size, years of exposure, method of exposure assessment (in-person interview, phone interview, and self-administered questionnaire), matching factors and covariates for adjustment, and risk estimates with corresponding $95 \%$ CIs. The quality of included studies was assessed using the NewcastleOttawa Scale (NOS). The NOS yields results from zero to nine stars. When the study obtains more than six stars, it is considered to be of relatively high quality. Otherwise, it is considered to have relatively low quality.

\section{Statistical Analysis}

All statistical analyses were performed using Stata software (StataCorp LLC, College Station, TX, USA). The adjusted OR for the study was extracted for the metaanalysis; however, when unavailable, raw data were used. A random-effects model to combine the heterogeneity within and between studies was used to aggregate risk estimates. The statistical heterogeneity between the studies was evaluated using the $\mathrm{Q}$ statistic and the I-square statistic. For the $\mathrm{Q}$ statistic, $\mathrm{p}>0.1$ was considered statistically unimportant. For the I-square statistic, I-square $<50 \%$ was considered statistically unimportant.

To reduce intragroup heterogeneity, we conducted subgroup analyses according to the research design and geographic area.

We performed sensitivity analysis to assess the impact of individual studies on the overall results. After excluding studies with influential heterogeneity, we re-analyzed the overall studies. 
Given the possible publication bias between studies, we also conducted publication bias analysis using an Egger's test or Begg's funnel chart. For the Egger's test, $\mathrm{p}<0.05$ was considered statistically significant.

Finally, we use the Grading of Recommendations Assessment, Development and Evaluation (GRADE) method to assess certainty (or confidence) in the body of evidence for an outcome.

As the most common definition of well-water consumption is ever intake of well water, our main analysis was ever use of well water as a water source versus never using well water. Positive exposure was defined as the continuous use of well water for drinking water for 6 months or for 1 year more ever in one's life. Studies with other exposure standards and those with extremely large sample sizes are discussed separately.

\section{Results}

\section{Search Results and Description of Studies}

Figure 1 presents the flowchart of the study selection process. The literature search yielded a total of 758 articles: 514 from PubMed, 108 from EMBASE, 6 from Cochrane, and 130 from EBSCO. After careful review, 32 studies were identified for full-text assessment. Seventeen of the 32 studies were further excluded for the following reasons: unable to find the full text, ${ }^{5,17-20}$ unable to extract valid outcome data, ${ }^{21-29}$ the language used was not English, ${ }^{30}$ the sample size was too large ${ }^{31}$ and quality evaluation was too low. ${ }^{32}$ Therefore, a total 15 studies included data suitable for our meta-analysis. ${ }^{6-15,33-37}$ Studies were published from 1990 to 2014. Of the 15 studies, three originated from the United States, ${ }^{7,9,15}$ three from Italy, ${ }^{6,14,33}$ one from Serbia, ${ }^{10}$ two from Canada, ${ }^{34,35}$ two from China, ${ }^{12,37}$ one from Spain, ${ }^{36}$ one from Korea, ${ }^{8}$ and two from India. ${ }^{11,13}$ The vast majority of study participants were diagnosed according to symptoms. Of the 15 studies, 13 provided data on the continuous use of well water as drinking water, including 8 with ever well-water consumption, ${ }^{7-9,12,14,15,36,37}$ one with 6 months or more, ${ }^{10}$ three with 1 year or more, ${ }^{6,13,35}$ and one with 5 years or more of well-water consumption; ${ }^{11}$ two studies provided data on ever use of well water as drinking water before age 15 years and before 20 years old. ${ }^{33,34}$ Controls were recruited randomly from hospitals or the general population. Data were ascertained in telephone interviews, in-person interviews, or self-administered questionnaires. Further details of the included studies are shown in Table 1.

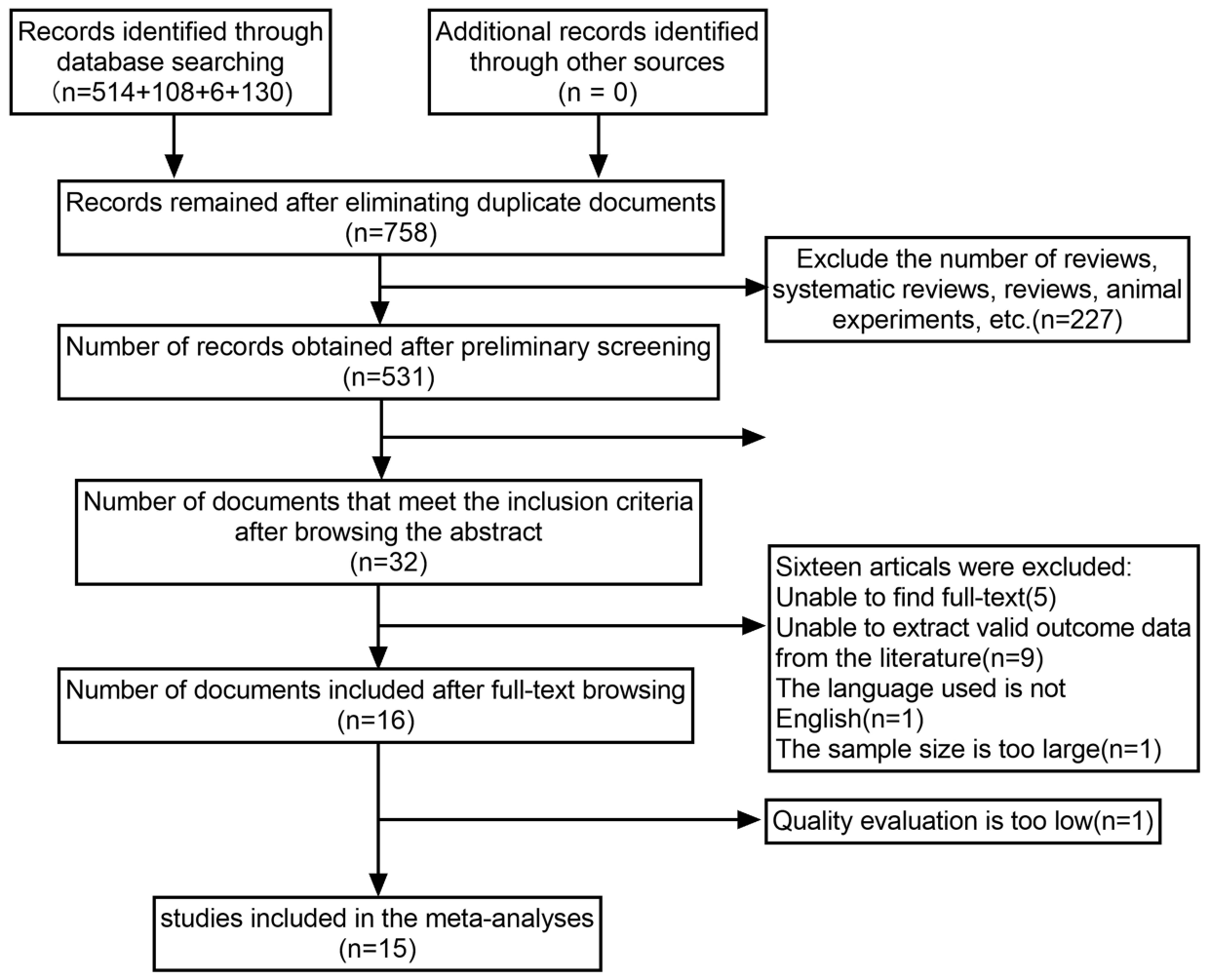

Figure I Flow diagram of study selection. 
Table I Characteristics of Studies Included in the Meta-Analysis

\begin{tabular}{|c|c|c|c|c|}
\hline Study & Selection & Comparability & Exposure & Total Score \\
\hline Liou $1997^{12}$ & $\star \star$ & $\star \star$ & $\star$ & 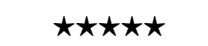 \\
\hline Behari $200 \mathrm{I}^{13}$ & $\star \star \star$ & $\star \star$ & $\star$ & 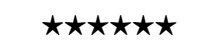 \\
\hline Michele $1996^{6}$ & $\star \star \star$ & $\star \star$ & $\star$ & 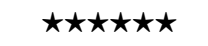 \\
\hline Zorzon $2002^{33}$ & $\star \star \star$ & $\star \star$ & $\star$ & 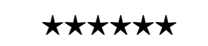 \\
\hline Cho $2008^{8}$ & $\star \star \star$ & $\star$ & $\star$ & 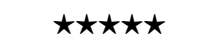 \\
\hline Hristina $2010^{10}$ & $\star \star \star$ & $\star \star$ & $\star$ & 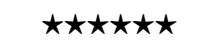 \\
\hline Morano $1994^{36}$ & $\star \star \star$ & $\star \star$ & $\star$ & 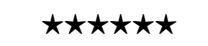 \\
\hline Hancock $2008^{15}$ & $\star \star \star$ & $\star \star$ & $\star$ & 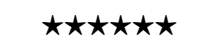 \\
\hline Firestone $2005^{7}$ & $\star \star \star$ & $\star \star$ & $\star \star$ & 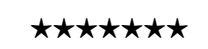 \\
\hline Wang $1993^{37}$ & $\star \star \star$ & $\star \star$ & $\star$ & 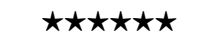 \\
\hline Sanyal $2010^{11}$ & $\star \star \star$ & $\star \star$ & $\star$ & 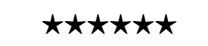 \\
\hline Semchuk $1995^{34}$ & $\star \star \star \star$ & $\star \star$ & $\star \star \star$ & 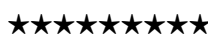 \\
\hline Nuti $2004^{14}$ & $\star \star \star \star$ & $\star \star$ & $\star \star$ & 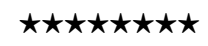 \\
\hline Gatto $2009^{9}$ & $\star \star \star \star$ & $\star \star$ & $\star \star \star$ & 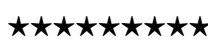 \\
\hline Wang $1994^{35}$ & $\star \star \star \star$ & $\star \star$ & $\star \star \star$ & 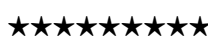 \\
\hline
\end{tabular}

Notes: One " $\star$ " will be given if one standard is reached. The more stars, the better the quality of the research.

As shown in Tables 2, 13 studies had six or more stars according to the NOS, indicating that the overall quality of the studies was relatively high.

\section{Overall Association of Well-Water Consumption and Risk of Parkinson's \\ Disease}

Twelve studies evaluated the association between ever using well water as a water source and the risk of PD. The pooled OR was 1.25 (95\% CI: 1.01-1.53, $\mathrm{p}$ for heterogeneity $=0.003, \mathrm{I}^{2}=61.2 \%$ ), with $\mathrm{p}<0.1$ and $\mathrm{I}^{2}$ $>50 \%$. This suggested that the heterogeneity between the selected documents in this study was statistically significant. Next, subgroup analysis and sensitivity analysis were used to determine the reasons for the heterogeneity (Table 3). Studies with other exposure standards and those with extremely large sample sizes are discussed separately. (For example, three studies were excluded from the evaluation temporarily owing to a more restrictive definition of positive exposure). ${ }^{11,33,34}$

Table 2 Quality Analysis Diagrams of the Included Studies

\begin{tabular}{|c|c|c|c|c|c|c|c|}
\hline Study & Country & Design & Sample Size & Blind Method & Adjustments & Exposure Definition & Study Quality \\
\hline Liou $1997^{12}$ & China & $\mathrm{HCC}$ & $120 / 240$ & $\mathrm{~N}$ & $\mathrm{I}, 2$ & Ever & 5 \\
\hline Behari $2001^{13}$ & India & $\mathrm{HCC}$ & $377 / 377$ & $\mathrm{~N}$ & 2 & $>$ lyear & 6 \\
\hline Michele $1996^{6}$ & Italy & $\mathrm{HCC}$ & $116 / 116$ & $\mathrm{~N}$ & $\mathrm{I}, 2,3$ & $>$ lyear & 6 \\
\hline Zorzon $2002^{33}$ & Italy & $\mathrm{HCC}$ & $136 / 272$ & $\mathrm{~N}$ & 1,2 & Before 20 years old & 5 \\
\hline Cho $2008^{8}$ & Korea & $\mathrm{HCC}$ & $235 / 77$ & $\mathrm{~N}$ & 5 & Ever & 5 \\
\hline Hristina $2010^{10}$ & Serbia & $\mathrm{HCC}$ & $110 / 220$ & $\mathrm{~N}$ & $1,2,5$ & $>6$ mouths & 6 \\
\hline Morano $1994^{36}$ & Spain & $\mathrm{HCC}$ & $74 / 148$ & $\mathrm{~N}$ & 1 & $>$ lyear & 6 \\
\hline Hancock $2008^{15}$ & USA & PCC & $319 / 296$ & $\mathrm{~N}$ & 4 & Ever & 6 \\
\hline Firestone $2005^{7}$ & USA & $\mathrm{HCC}$ & $250 / 388$ & $\mathrm{~N}$ & 1,2 & Ever & 7 \\
\hline Wang $1993^{37}$ & China & $\mathrm{HCC}$ & $93 / 186$ & $\mathrm{~N}$ & 1,2 & Ever & 6 \\
\hline Sanyal $2010^{11}$ & India & $\mathrm{HCC}$ & $175 / 350$ & $\mathrm{~N}$ & $1,2,4$ & $>5$ years & 6 \\
\hline Semchuk $1995^{34}$ & Canada & PCC & $97 / 194$ & $Y$ & 1,2 & Before 15 years old & 9 \\
\hline Nuti $2004^{14}$ & Italy & PCC & $190 / 190$ & $\mathrm{~N}$ & $1,2,6$ & Ever & 8 \\
\hline Gatto $2009^{9}$ & USA & PCC & $368 / 341$ & $Y$ & 2,5 & Ever & 9 \\
\hline Wang $1994^{35}$ & Canada & PCC & $40 / 97$ & $Y$ & 4 & Ever & 9 \\
\hline
\end{tabular}

Note: Matching or adjustments were: (I) sex, (2) age, (3) institution, (4) gene, (5) residential area, (6) socio-cultural factors.

Abbreviations: PCC, population-based case-control study; HCC, hospital-based case-control study. 
Table 3 Results of Subgroup Analyses Stratified by Studied Design, Geographic Area and Study Quality

\begin{tabular}{|c|c|c|c|c|c|}
\hline \multirow[t]{2}{*}{ Group } & \multirow[t]{2}{*}{ Number of Studies } & \multicolumn{2}{|c|}{ Summary Effect } & \multicolumn{2}{|c|}{ Heterogeneity } \\
\hline & & OR(95\% CI) & $p$ value & I-Squared & $p$ \\
\hline All studies & 12 & $1.245(1.011-1.533)$ & 0.039 & $61.2 \%$ & 0.003 \\
\hline \multicolumn{6}{|c|}{ Study design } \\
\hline $\mathrm{HCC}$ & 8 & $1.47 \mid(1.124-1.923)$ & 0.005 & $61.1 \%$ & 0.012 \\
\hline PCC & 4 & $0.962(0.734-\mid .26 I)$ & 0.781 & $41.1 \%$ & 0.165 \\
\hline \multicolumn{6}{|c|}{ Geographic area } \\
\hline America & 4 & $0.969(0.757-1.240)$ & 0.803 & $41.2 \%$ & 0.164 \\
\hline Asia & 4 & $1.286(1.045-1.582)$ & 0.017 & $0.0 \%$ & 0.460 \\
\hline Europe & 4 & $1.798(1.014-3.187)$ & 0.045 & $73.2 \%$ & 0.011 \\
\hline \multicolumn{6}{|c|}{ Study quality } \\
\hline High & 4 & $0.919(0.7 \mid 7-1.179)$ & 0.507 & $32.3 \%$ & 0.219 \\
\hline Low & 8 & I.495(I.|77-I.898) & 0.001 & $50.9 \%$ & 0.047 \\
\hline
\end{tabular}

\section{Stratifying Analysis}

A significant association was observed for hospital-based case-control studies (HCC) (OR 1.47, 95\% CI: 1.12-1.92, $\mathrm{I}^{2}=61.1 \%, \mathrm{p}$ for heterogeneity $=0.012$ ) whereas no significant association was detected for population-based case-control studies (PCC) (OR 0.96, 95\% CI: 0.73-1.26, $\mathrm{I}^{2}=41.1 \%, \mathrm{p}$ for heterogeneity $\left.=0.165\right)$. The heterogeneity of research subgroups designed by PPC was lower than the risk value, but the heterogeneity of HCC was still high, considering that there may be other confounding factors leading to the heterogeneity.

In stratification by geographic area, the pooled ORs were 0.97 (95\% CI: $0.76-1.24, \mathrm{I}^{2}=41.2 \%$, p for heterogeneity $=0.164), 1.29\left(95 \%\right.$ CI: $1.05-1.58, \mathrm{I}^{2}=0.0 \%$, $\mathrm{p}$ for heterogeneity $=0.460)$, and $1.80(95 \% \mathrm{CI}: 1.01-3.19$, $\mathrm{I}^{2}=73.2 \%, \mathrm{p}$ for heterogeneity $\left.=0.011\right)$ for North America, Asia, and Europe, respectively. After stratified analysis, the heterogeneity of studies conducted in North America and Asia was low. However, owing to the large heterogeneity of the overall data and the data in Europe, we considered that other heterogeneities were present in the included literature.

\section{Sensitivity Analysis}

The results of sensitivity analysis showed that Hristina 2010 had a large influence on heterogeneity (Figure 2). After removing this study, the combined effect of the variables on the meta-analysis was very large. Therefore, we again reviewed this article and decided to delete it.
For the remaining 11 documents, summary statistics for each group and an effect estimate and its precision were calculated, as presented in Table 4. After removing the study, the heterogeneity test was performed again; the results showed that the heterogeneity of the remaining 11 articles was reduced $\left(\mathrm{I}^{2}=44.5 \%, \mathrm{p}=0.054\right)$; however, the heterogeneity was still statistically significant. Figure 3 presents forest plots for ever well-water drinkers versus non-drinkers. The pooled RR was 1.16 (95\% CI: $0.97-$ $1.39, I^{2}=44.52 \%, p$ for heterogeneity $\left.=0.054\right)$. Then the remaining 11 documents were analyzed in a stratified manner (Table 5).

Compared with the previous stratified analysis, the intra-group heterogeneity of the HCC design in the study

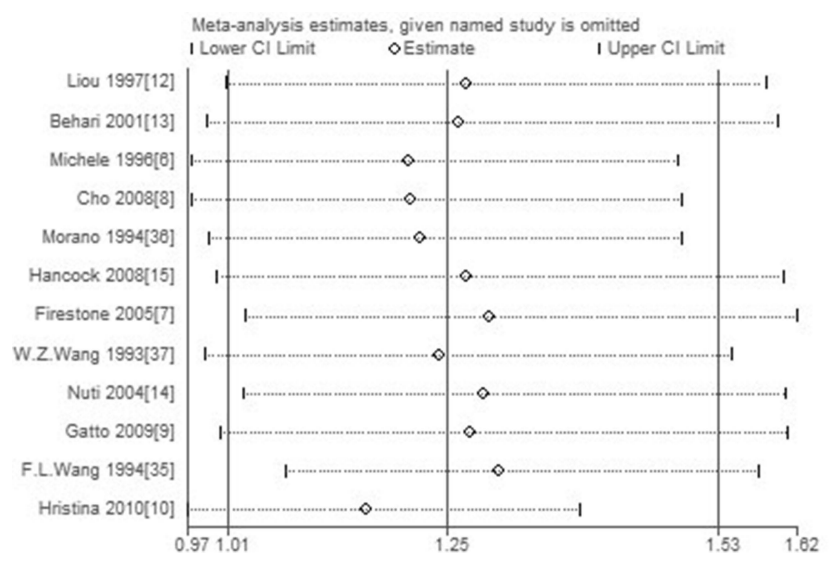

Figure 2 Sensitivity analysis. Abbreviation: $\mathrm{Cl}$, confidence interval. 
Table 4 Results of Individual Studies

\begin{tabular}{|c|c|c|c|c|c|c|}
\hline Study & Country & Tevent & Tnoevent & Cevent & Cnoevent & OR $(95 \% \mathrm{Cl})$ \\
\hline Liou $1997^{12}$ & China & 90 & 30 & 177 & 63 & I.07(0.65, I.77) \\
\hline Behari $200 \mathrm{I}^{13}$ & India & 156 & 221 & 140 & 237 & I.19(0.89,1.60) \\
\hline Michele $1996^{6}$ & Italy & 51 & 65 & 68 & 264 & I.89(1.10,3.26) \\
\hline Cho $2008^{8}$ & Korea & 34 & 102 & 35 & 237 & I.83(I.08,3.08) \\
\hline Morano $1994^{36}$ & Spain & 156 & 79 & 40 & 37 & $3.28(0.93,|| .5 \mid)$ \\
\hline Hancock $2008^{15}$ & USA & 76 & 34 & 102 & 118 & I.I2(0.8I, I.54) \\
\hline Firestone $2005^{7}$ & USA & 71 & 3 & 130 & 18 & $0.94(0.69,1.30)$ \\
\hline Wang $1993^{37}$ & China & 197 & 122 & 175 & 121 & I.39(0.84,2.29) \\
\hline Nuti $2004^{14}$ & Italy & 133 & 117 & 212 & 176 & $0.93(0.59,1.44)$ \\
\hline Gatto $2009^{9}$ & USA & 45 & 48 & 75 & 111 & I.09(0.79, I.50) \\
\hline Wang $1994^{35}$ & Canada & 32 & 10 & 60 & 24 & $0.45(0.21,0.96)$ \\
\hline
\end{tabular}

design group analysis was reduced $\left(\mathrm{I}^{2}=40.9 \%\right.$, $\mathrm{p}$ for heterogeneity $=0.118$ ), which was no longer statistically significant. It can be concluded from the table that the subgroup with an HCC design showed a positive correlation between the use of well water and PD (OR 1.31, 95\% CI: $1.04-1.65, \mathrm{I}^{2}=40.9 \%, \mathrm{p}$ for heterogeneity $=0.118$ ) whereas studies with a PCC design showed no link between them (OR 0.96, 95\% CI: $0.73-1.26, \mathrm{I}^{2}=41.1 \%$, $\mathrm{p}$ for heterogeneity $=0.165$ ). The results of subgroups based on geographic area showed that studies from North America generally did not find that the use of well water is related to PD (OR 0.97, 95\% CI: 0.76-1.24, $\mathrm{I}^{2}=41.2 \%$, $\mathrm{p}$ for heterogeneity $=0.164)$ whereas Asian studies reported that these are positively related (OR 1.29, 95\% CI: $1.05-1.58, \mathrm{I}^{2}=0.0 \%, \mathrm{p}$ for heterogeneity $=0.460$ ). The results of European studies were unreliable owing to the high degree of heterogeneity.

As controls in HCC-design studies were more likely to go to a hospital, HCC-design studies can be more biased than PCC-design studies, which may lead to different conclusions. When it comes to subgroup analysis by geographic area, although we consider that an association

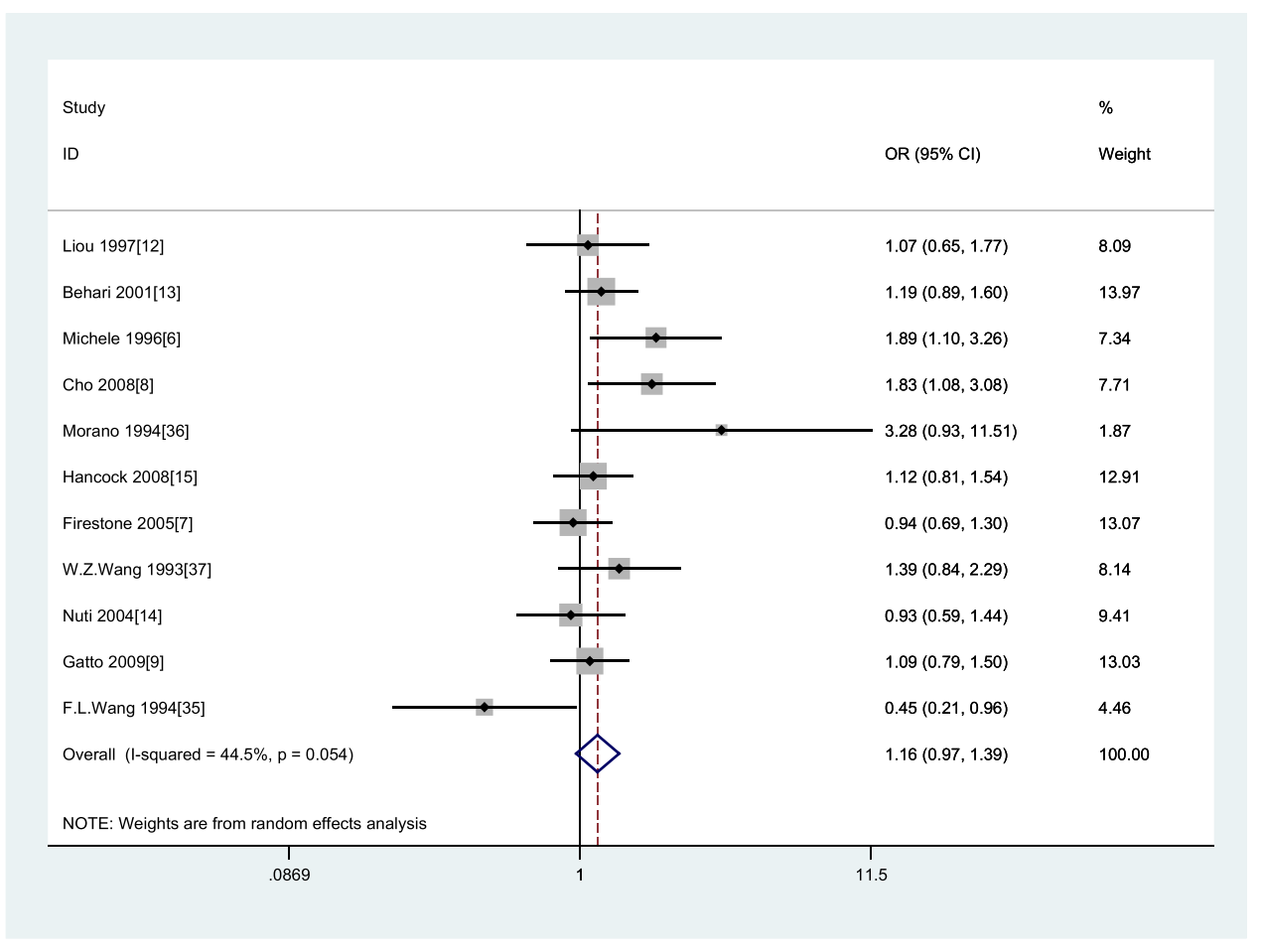

Figure 3 Forest plots for ever-well-water drinkers versus non-drinkers $(95 \% \mathrm{Cl})$.

Abbreviations: $\mathrm{Cl}$, confidence interval; OR, odd ratio. 
Table 5 Results of Subgroup Analyses Stratified by Studied Design, Geographic Area and Study Quality

\begin{tabular}{|c|c|c|c|c|c|}
\hline \multirow[t]{2}{*}{ Group } & \multirow[t]{2}{*}{ Number of Studies } & \multicolumn{2}{|c|}{ Summary Effect } & \multicolumn{2}{|c|}{ Heterogeneity } \\
\hline & & OR(95\% Cl) & $p$ value & I-Squared & $p$ \\
\hline All studies & 11 & I.I58(0.968-I.386) & 0.109 & $44.52 \%$ & 0.054 \\
\hline \multicolumn{6}{|c|}{ Study design } \\
\hline $\mathrm{HCC}$ & 7 & I.3I4(I.044-I.654) & 0.020 & $40.9 \%$ & 0.118 \\
\hline PCC & 4 & $0.962(0.734-1.261)$ & $0.78 \mathrm{I}$ & $41.1 \%$ & 0.165 \\
\hline \multicolumn{6}{|c|}{ Geographic area } \\
\hline America & 4 & $0.969(0.757-1.240)$ & 0.803 & $41.2 \%$ & 0.164 \\
\hline Asia & 4 & $1.286(1.045-1.582)$ & 0.017 & $0.0 \%$ & 0.460 \\
\hline Europe & 3 & $1.542(0.793-3.001)$ & 0.202 & $67.6 \%$ & 0.046 \\
\hline \multicolumn{6}{|c|}{ Study quality } \\
\hline High & 4 & $0.919(0.7 \mid 7-1.179)$ & 0.507 & $32.3 \%$ & 0.219 \\
\hline Low & 7 & $1.33 \mathrm{I}(1.100-1.6 \mathrm{II})$ & 0.003 & $18.6 \%$ & 0.288 \\
\hline
\end{tabular}

between well-water exposure and PD risk cannot be established, we assume that the association between well-water use and PD cannot be ruled out in a specific, small geographic area.

\section{Publication Bias and Certainty of Evidence}

The Begg's funnel plot did not show any asymmetry (Figure 4), indicating that no evidence of publication bias was detected. Additionally, the Egger's test suggested that there was no publication bias ( $p$ for Egger's test $=0.458$ ). The GRADE method was used to evaluate the evidence. Though the included studies were all case-control studies and did not meet the requirements of increasing the evidence, we believe that the level of evidence is high, since

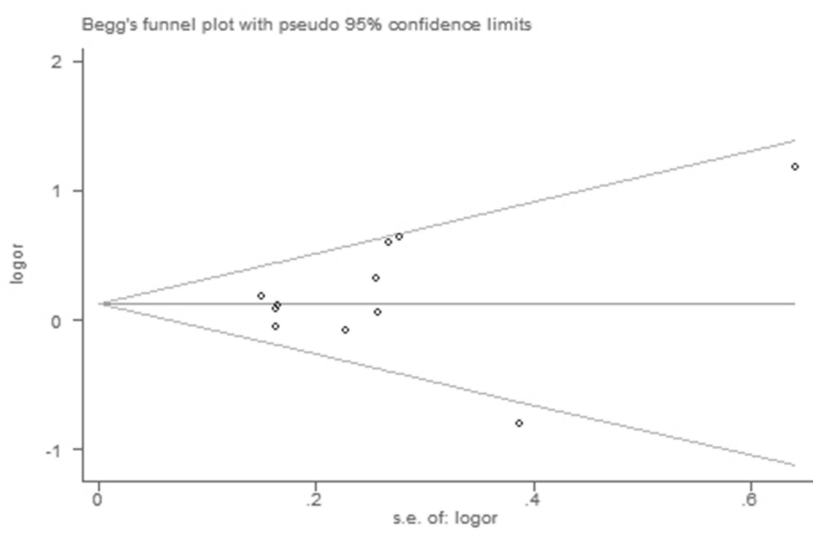

Figure 4 Funnel plot analysis to detect publication bias. the interest here is not a factor particularly susceptible to recall bias.

\section{Discussion}

Our research shows that, in general, it cannot be considered that there is an association between well-water exposure and PD risk. However, in the subgroup analysis according to a specific experimental design (such as HCC) or a specific location (such as Asia), certain conclusions about this association can be drawn.

When studies with a narrower definition of exposure were included in the analysis, we found one study reporting that people with a history of drinking well water for more than 5 years were more likely to develop PD, ${ }^{11}$ and another study found that people who drank well water for their first 20 years of life were more likely to develop PD, ${ }^{33}$ These findings suggest that the standards selected for positive exposure may affect the final conclusions. However, a high-quality study with a PCC design claimed that drinking well water during the first 15 years of life is unrelated to the prevalence of $\mathrm{PD},{ }^{34}$ this conclusion contradicts previous studies, highlighting the need for further research.

The association between well-water consumption and risk of PD has long been explored, with conflicting results. So far, many studies have shown that the use of well water may increase the risk of $\mathrm{PD},{ }^{6-11}$ but other studies have observed a reverse correlation or no correlation. ${ }^{12-15}$ The aim of this study was to attempt to clarify whether there is a correlation between the use of well water and PD. We 
conclude that an association between well-water exposure and PD risk cannot be clearly established; however, various mechanisms have been proposed. There are many environmental factors that may cause an increased incidence of PD., ${ }^{4,42}$ Among these, rural residence and pesticide use have been proved in many studies to have a positive correlation with $\mathrm{PD},{ }^{25,43-46,48}$ these factors are highly related to the use of well water, which suggests that they may be distorting factors that influence investigation of the relationship between well-water drinking and PD. In fact, some studies have reported that the positive correlation between well water and PD is caused by well water as a carrier of pesticides. ${ }^{45}$ Studies have shown that harmful substances in well water that are related to PD may include rotenone, paraquat and so on. Take rotenone as an example, it is a naturally occurring insecticide and it has been proved that even at a low free rotenone concentration of about $20-30 \mathrm{nmol} / \mathrm{L}$ in the brain, the binding of specific complex I can be reduced by $75 \%$, accompanied by dopaminergic lesions of the substantia nigra striatum. ${ }^{48}$ Therefore, we suppose that the correlation between well water and PD depends on the pesticide content in well water, to some extent, which can explain the clustering of PD cases in a small area. ${ }^{47}$

A nationwide case-control study published in 2020, which was excluded in this study because the sample size was too large, also reported that reliance on well water does not appear to increase risk of PD in general, ${ }^{31}$ which further increases the credibility of our conclusions. In this nationwide, population-based case-control study, the researchers identified all incident PD cases $(\mathrm{N}=89,790)$ and all comparable controls $(\mathrm{N}=21,549,400)$ age $66-90$ who solely relied on Medicare coverage in the US in 2009. After careful research, they came to the conclusion that use of well water was inversely associated with $\mathrm{PD}$ risk $(\mathrm{OR}=0.87,95 \% \mathrm{CI}$ $0.85-0.89$ ), which is quite surprising. The study then proposed that solvents in private wells in the United States is usually lower than the federal drinking water standards, in which case well water may be considered even a poor indicator of the content of such chemicals in drinking water, which may be a reason leading to the above irrelevant conclusion.

In combination with our study, the low pesticide content in well water in the United States may also be a reason why the conclusions obtained in studies from North America were inconsistent with those conducted in Asia. Take China as an example, studies have shown that, compared with developed countries, China's pesticide registration system, operating license system and other systems have been established late, with poor practical experience and effects. ${ }^{49}$ Meanwhile, China's pesticide application is large and the pesticide application load per unit of arable land is high. It is 3.42 and 3.11 times for the total application of pesticides and its load in China than that in the developed countries, which may result in a higher concentration of harmful substances in the well water in China than in North America, making the results different.

We can see that there is a big flaw in observational research that bias counts a lot. During the research process, we found that many studies did not measure the content of the main harmful substances in the well water, which can be quite distorting factors. As a result, it can lead to a certain deviation in the definition of well water, which may be the main reason for the different results.

Also, the researches of PCC design are less biased than the experimental design of $\mathrm{HCC}$, which is consistent with our conclusion, so the PCC-designed studies should be given more weight when the conclusions are contradictory, which gives our conclusions greater credibility.

To conclude, these findings further support our guess that whether the well water itself is positively correlated with PD is likely to be related to the level of harmful substances in the well water, and we cannot conclude that there is correlation between well water and PD in a wider area.

Several limitations in our analysis should be addressed. First, because our meta-analysis was based on observational studies, distorting factors are of concern, which has been discussed above. Second, the included studies applied strict standards, especially for positive exposure, which may have led to some studies being missed. This could result in insufficient research results included in our analysis. Third, we were unable to quantitatively assess the relationship between the number of years of well-water consumption and the incidence of PD owing to limited available data. Fourth, a separate analysis for women and men was not possible as only two studies provided results separately for men and women. ${ }^{6,7}$ Finally, potential publication bias may distort the association between wellwater consumption and risk of PD.

To conclude, firstly, we found reliance on well water does not appear to increase risk of PD in general, which is contrary to the mainstream notion. Secondly, we pointed out the reasons why previous studies have reached different conclusions, hopefully it will remind researchers who 
are engaged in similar research to heed. Thirdly, we hope to encourage people and public management departments to pay attention to the impact of pesticides and other pollution on land and water sources. It is not our final purpose to simply conclude that there is no significant correlation between well-water consumption and PD risk, but why the impact of well water in different regions on PD is different is what we most want to remind the public. This conclusion can be used as a reference for health systems when making policies.

\section{Conclusions}

This meta-analysis provides evidence of a lack of association between well-water consumption and risk of PD.

\section{Data Sharing Statement}

Template data collection forms, data extracted from the included studies, data used for all analyses, analytic code, and any other materials used in the review are all publicly available.

\section{Registration and Protocol}

The protocol is described in the Methods. Registration does not apply.

\section{Acknowledgment}

We thank Analisa Avila, ELS, of Liwen Bianji (Edanz) (www.liwenbianji.cn/ac) for editing the English text of a draft of this manuscript.

\section{Funding}

This research did not receive any specific grant from funding agencies in the public, commercial, or not-forprofit sectors.

\section{Disclosure}

The authors declare no conflict of interest.

\section{References}

1. de Lau LML, Breteler MMB. Epidemiology of Parkinson's disease. Lancet Neurol. 2006;5(6):525-535. doi:10.1016/S1474-4422(06) 70471-9

2. Ascherio A, Schwarzschild MA. The epidemiology of Parkinson's disease: risk factors and prevention. Lancet Neurol. 2016;15 (12):1257-1272. doi:10.1016/S1474-4422(16)30230-7

3. Broussolle E, Thobois S. [Genetics and environmental factors of Parkinson disease]. Rev Neurol (Paris). 2002;158 Spec no 1:S11-23. French.
4. Schoenberg BS. Environmental risk factors for Parkinson's disease: the epidemiologic evidence. Can J Neurol Sci. 1987;14(3): SUPPL.):407-13. doi:10.1017/S0317167100037811

5. Ravan AA, Sankhla CS, Gadhari M. Analysis of age of onset and epidemiological factors in Parkinson's disease. Parkinsonism Relat Disord. 2012;18:S11-S2. doi:10.1016/S1353-8020(11)70121-3

6. De Michele G, Filla A, Volpe G, et al. Environmental and genetic risk factors in Parkinson's disease: a case-control study in Southern Italy. Mov Disorders. 1996;11(1):17-23. doi:10.1002/mds.870110105

7. Firestone JA, Smith-Weller T, Franklin G, Swanson P, Longstreth WT Jr, Checkoway H. Pesticides and risk of Parkinson disease: a population-based case-control study. Arch Neurol. 2005;62 (1):91-95. doi:10.1001/archneur.62.1.91

8. Cho J-W, Jeon BS, Jeong D, et al. Association between parkinsonism and participation in agriculture in Korea. J Clin Neurol. 2008;4 (1):23-28. doi:10.3988/jen.2008.4.1.23

9. Gatto NM, Cockburn M, Bronstein J, Manthripragada AD, Ritz B. Well-water consumption and Parkinson's disease in rural California. Environ Health Perspect. 2009;117(12):1912-1918. doi:10.1289/ ehp. 0900852

10. Hristina VD, Sipetic SB, Maksimovic JM, et al. Environmental factors and Parkinson's disease: a case-control study in Belgrade, Serbia. Int $J$ Neurosci. 2010;120(5):361-367. doi:10.3109/ 00207451003668374

11. Sanyal J, Chakraborty DP, Sarkar B, et al. Environmental and familial risk factors of Parkinsons disease: case-control study. Can J Neurol Sci. 2010;37(5):637-642. doi:10.1017/S0317167100010829

12. Liou HH, Tsai MC, Chen CJ, et al. Environmental risk factors and Parkinson's disease: a case-control study in Taiwan. Neurology. 1997;48(6):1583-1588. doi:10.1212/WNL.48.6.1583

13. Behari M, Srivastava AK, Das RR, Pandey RM. Risk factors of Parkinson's disease in Indian patients. J Neurol Sci. 2001;190(12):49-55. doi:10.1016/S0022-510X(01)00578-0

14. Nuti A, Ceravolo R, Dell'Agnello G, et al. Environmental factors and Parkinson's disease: a case-control study in the Tuscany region of Italy. Parkinsonism Relat Disord. 2004;10(8):481-485. doi:10.1016/j. parkreldis.2004.01.008

15. Hancock DB, Martin ER, Mayhew GM, et al. Pesticide exposure and risk of Parkinson's disease: a family-based case-control study. $B M C$ Neurol. 2008;8:8. doi:10.1186/1471-2377-8-8

16. Breckenridge CB, Berry C, Chang ET, Sielken RL Jr, Mandel JS. Association between Parkinson's disease and cigarette smoking, rural living, well-water consumption, farming and pesticide use: systematic review and meta-analysis. PLoS One. 2016;11(4):e0151841. doi:10.1371/journal.pone. 0151841

17. Das K, Ghosh M, Nag C, et al. Role of familial, environmental and occupational factors in the development of Parkinson's disease. Neurodegener Dis. 2011;8(5):345-351. doi:10.1159/000323797

18. Smargiassi A, Mutti A, De Rosa A, De Palma G, Negrotti A, Calzetti S. A case-control study of occupational and environmental risk factors for Parkinson's disease in the Emilia-Romagna region of Italy. NeuroToxicology. 1998;19(4-5):709-712.

19. Marder K, Logroscino G, Alfaro B, et al. Environmental risk factors for Parkinson's disease in an urban multiethnic community. Neurology. 1998;50(1):279-281. doi:10.1212/WNL.50.1.279

20. Gorell JM, Johnson CC, Rybicki BA, Peterson EL, Richardson RJ. The risk of Parkinson's disease with exposure to pesticides, farming, well water, and rural living. Neurology. 1998;50(5):1346-1350. doi:10.1212/WNL.50.5.1346

21. Cagac A. Farming, well water consumption, rural living, and pesticide exposure in early life as the risk factors for Parkinson disease in Igdir province. Neurosciences (Riyadh, Saudi Arabia). 2020;25 (2):129-133. doi:10.17712/nsj.2020.2.20190104

22. Engel LS, Checkoway H, Keifer MC, et al. Parkinsonism and occupational exposure to pesticides. Occup Environ Med. 2001;58 (9):582-589. doi:10.1136/oem.58.9.582 
23. Vieregge P, Heinzow B, Korf G, Teichert HM, Schleifenbaum P, Mosinger HU. Long term exposure to manganese in rural well water has no neurological effects. Can J Neurol Sci. 1995;22 (4):286-289. doi:10.1017/S0317167100039482

24. Jiménez-Jiménez FJ, Mateo D, Giménez-Roldán S. Exposure to well water and pesticides in Parkinson's disease: a case-control study in the Madrid area. Movement Disord. 1992;7(2):149-152. doi:10.1002/ mds. 870070209

25. Rajput AH, Uitti RJ, Stern W, et al. Geography, drinking water chemistry, pesticides and herbicides and the etiology of Parkinson's disease. Can J Neurol Sci. 1987;14(3SUPPL.):414-418. doi:10.1017/ S0317167100037823

26. Rajput AH, Uitti RJ, Stern W, Laverty W. Early onset Parkinson's disease in Saskatchewan - Environmental considerations for etiology. Can J Neurol Sci. 1986;13(4):312-316. doi:10.1017/S0317167100036635

27. McCann SJ, LeCouteur DG, Green AC, et al. The epidemiology of Parkinson's disease in an Australian population. Neuroepidemiology. 1998;17(6):310-317. doi:10.1159/000026185

28. Dos Santos Werneck AL, Alvarenga H. Genetics, drugs and environmental factors in Parkinson's disease: a case control study. Arq Neuropsiquiatr. 1999;57(2B):347-355. doi:10.1590/S0004282X1999000300001

29. Gupta V, Garg RK, Pant KK, Khattri S. A study on risk factors for Parkinson's disease in Indian population. Bioinformation. 2014;10 (6):342-346. doi:10.6026/97320630010342

30. Zayed J, Ducic S, Campanella G, et al. Facteurs environnementaux dans l'étiologie de la maladie de Parkinson. Can J Neurol Sci/Journal Canadien Des Sciences Neurologiques. 2015;17(3):286-291. doi:10.1017/S0317167100030584

31. Silver MR, Racette BA, Dube U, Faust IM, Searles Nielsen S. Well water and Parkinson's disease in medicare beneficiaries: a nationwide case-control study. $J$ Parkinsons Dis. 2020;10(2):693-705. doi:10.3233/JPD-191793

32. Taylor CA, Saint-Hilaire MH, Cupples LA, et al. Environmental, medical, and family history risk factors for Parkinson's disease: a new England-based case control study. Am J Med Genetics. 1999;88(6):742-749.

33. Zorzon M, Capus L, Pellegrino A, Cazzato G, Zivadinov R. Familial and environmental risk factors in Parkinson's disease: a case-control study in north-east Italy. Acta Neurol Scand. 2002;105(2):77-82. doi:10.1034/j.1600-0404.2002.10040.x

34. Semchuk KM, Love EJ. Effects of agricultural work and other proxyderived case-control data on Parkinson's disease risk estimates. Am $J$ Epidemiol. 1995;141(8):747-754. doi:10.1093/oxfordjournals.aje. a117497

35. Wang FL, Semchuk KM, Love EJ. Reliability of environmental and occupational exposure data provided by surrogate respondents in a case-control study of Parkinson's disease. J Clin Epidemiol. 1994;47(7):797-807. doi:10.1016/0895-4356(94)90177-5
36. Morano A, Jimenez-Jimenez FJ, Molina JA, Antolin MA. Riskfactors for Parkinson's disease: case-control study in the province of Caceres, Spain. Acta Neurol Scand. 1994;89(3):164-170. doi:10.1111/j.1600-0404.1994.tb01655.x

37. Wang WZ, Fang XH, Cheng XM, Jiang DH, Lin ZJ. A case-control study on the environmental risk factors of Parkinson's disease in Tianjin, China. Neuroepidemiology. 1993;12(4):209-218. doi:10.1159/000110319

38. Tanner CM, Chen B, Wang WZ, et al. Environmental factors in the etiology of Parkinson's disease. Can J Neurol Sci. 1987;14(3 SUPPL.):419-423. doi:10.1017/S0317167100037835

39. Rybicki BA, Johnson CC, Uman J, Gorell JM. Parkinson's disease mortality and the industrial use of heavy metals in Michigan. Mov Disorders. 1993;8(1):87-92. doi:10.1002/mds.870080116

40. Priyadarshi A, Khuder SA, Schaub EA, Priyadarshi SS. Environmental risk factors and Parkinson's disease: a meta analysis. Environ Res. 2001;86(2):122-127. doi:10.1006/enrs.2001.4264

41. Sherer TB, Betarbet R, Greenamyre JT. Environment, mitochondria, and Parkinson's disease. Neuroscientist. 2002;8(3):192-197. doi:10.1177/1073858402008003004

42. Wright JM, Keller-Byrne J. Environmental determinants of Parkinson's disease. Arch Environ Occup Health. 2005;60(1):32-38. doi:10.3200/AEOH.60.1.32-38

43. Tanner CM. The role of environmental toxins in the etiology of Parkinson's disease. Trends Neurosci. 1989;12(2):49-54. doi:10.1016/0166-2236(89)90135-5

44. Siqueira HH, Domingues D, Demleitner A, et al. Exposure to pesticides in individuals with Parkinson's disease. Mov Disorders. 2014;29:S550.

45. James KA, Hall DA. Groundwater pesticide levels and the association with Parkinson disease. Int J Toxicol. 2015;34(3):266-273. doi: $10.1177 / 1091581815583561$

46. Isotalo J, Vahlberg T, Kaasinen V. Unchanged long-term rural-tourban incidence ratio of Parkinson's disease. Mov Disorders. 2016;32(3):474-475. doi:10.1002/mds.26862

47. Herishanu YO, Goldsmith JR, Abarbanel JM, Weinbaum Z. Clustering of Parkinson's disease in southern Israel. Can J Neurol Sci. 1989;16(4):402-405. doi:10.1017/S0317167100029462

48. Brown TP, Rumsby PC, Capleton AC, Rushton L, Levy LS. Pesticides and Parkinson's disease-is there a link? Environ Health Perspect. 2006;114(2):156-164. doi:10.1289/ehp.8095

49. Guo L, Wang Y. Analysis of pesticide regulatory system and application status in China, America, France and South Korea. Pesticides. 2018;57(05):359-366.
Neuropsychiatric Disease and Treatment

\section{Publish your work in this journal}

Neuropsychiatric Disease and Treatment is an international, peerreviewed journal of clinical therapeutics and pharmacology focusing on concise rapid reporting of clinical or pre-clinical studies on a range of neuropsychiatric and neurological disorders. This journal is indexed on PubMed Central, the 'PsycINFO' database and CAS, and is the official journal of The International Neuropsychiatric Association (INA). The manuscript management system is completely online and includes a very quick and fair peer-review system which is all easy to use. Visit http://www.dovepress.com/testimonials.php to read real quotes from published authors. 